\title{
PREVENTIVE MODEL ON QUALITY OF SERVICE IN IOT APPLICATIONS
}

\author{
T. MANIVANNAN ${ }^{1}$, DR. P. RADHAKRISHNAN ${ }^{2}$ \\ ${ }^{1}$ Assistant Professor, Research Department of Computer Science, Don Bosco College (Co-Ed), Guezou Nagar, \\ Yelagiri Hills, Tamil Nadu, India \\ ${ }^{2}$ Associate Professor, Research Department of Computer Science, Don Bosco College (Co-Ed), Guezou Nagar, \\ Yelagiri Hills, Tamil Nadu, India
}

\begin{abstract}
The Internet of Things (IoT) is a new paradigm that has changed the traditional way of living into a high tech life style. IoT applications such as smart homes and buildings, smart health care, smart environment, smart city, smart energy and grid, smart transportation and mobility, smart manufacturing and retail, smart agriculture, etc. are using billion devices and trillion sensors which generate enormous data with use of heterogeneous devices and networks every day. But an internet communication in IoT application creates a greater demand on the underlying communication, which affects the quality of service (QoS).QoS is another important factor for IoT can be defined as a measure to evaluate the quality, efficiency and performance of IoT devices, systems and architectures. The important and required QoS metrics for IoT applications are reliability, cost, energy consumption, security, availability and service time, end to end delay, throughput, jitter and packet delivery. With the increase in number of IoT device on the network, it has become essential to concentrate on QoS of devices and smooth data transformation over the networks. This research paper, surveying different challenges and key issues of IoT applications towards QoS such as reliability, interoperability, heterogeneity, energy, cost, security etc.Based on the survey identification we propose a better approach (or) model to reduce the QoS problems arrive in IoT applications. This research will also help the researchers to understand the challenges in various IoT applications and also discussedthe adaptive models to increase the QoS in IoT.
\end{abstract}

KEYWORDS: Quality of Service, Model, Wireless Sensor Network, IOT, Application

Received: Jun 01, 2020; Accepted: Jun 20, 2020; Published: Jun 26, 2020; Paper Id.: IJMPERDJUN2020109

\section{INTRODUCTION}

The IoT is referred as the Internet of devices, will make a huge difference in our life including ourselves. The Internet greatly affects training, correspondence, business, science, government, humankind and more [1]. Unmistakably, the Internet is significant and extraordinary manifestations in all of mankind's history and now with the idea of the IoT, web turns out to be increasingly ideal to have a keen life in each angle [2]. IoT is a most recent innovation of the Internet getting to. By the IoT, objects perceive themselves and acquire knowledge conduct by settling on or empowering related choices thinks to reality can convey data themselves. These things can get to data that has been amassed by further things, or they can add to different services[3]. This IoT will give the Quality of Service to true the applications such Smart Home and Buildings, Smart Energy and the Smart Grid, Smart Health, Smart Transportation and Mobility, Smart Factory and Smart Manufacturing, Smart Environment, Agriculture and more[4,5]. 


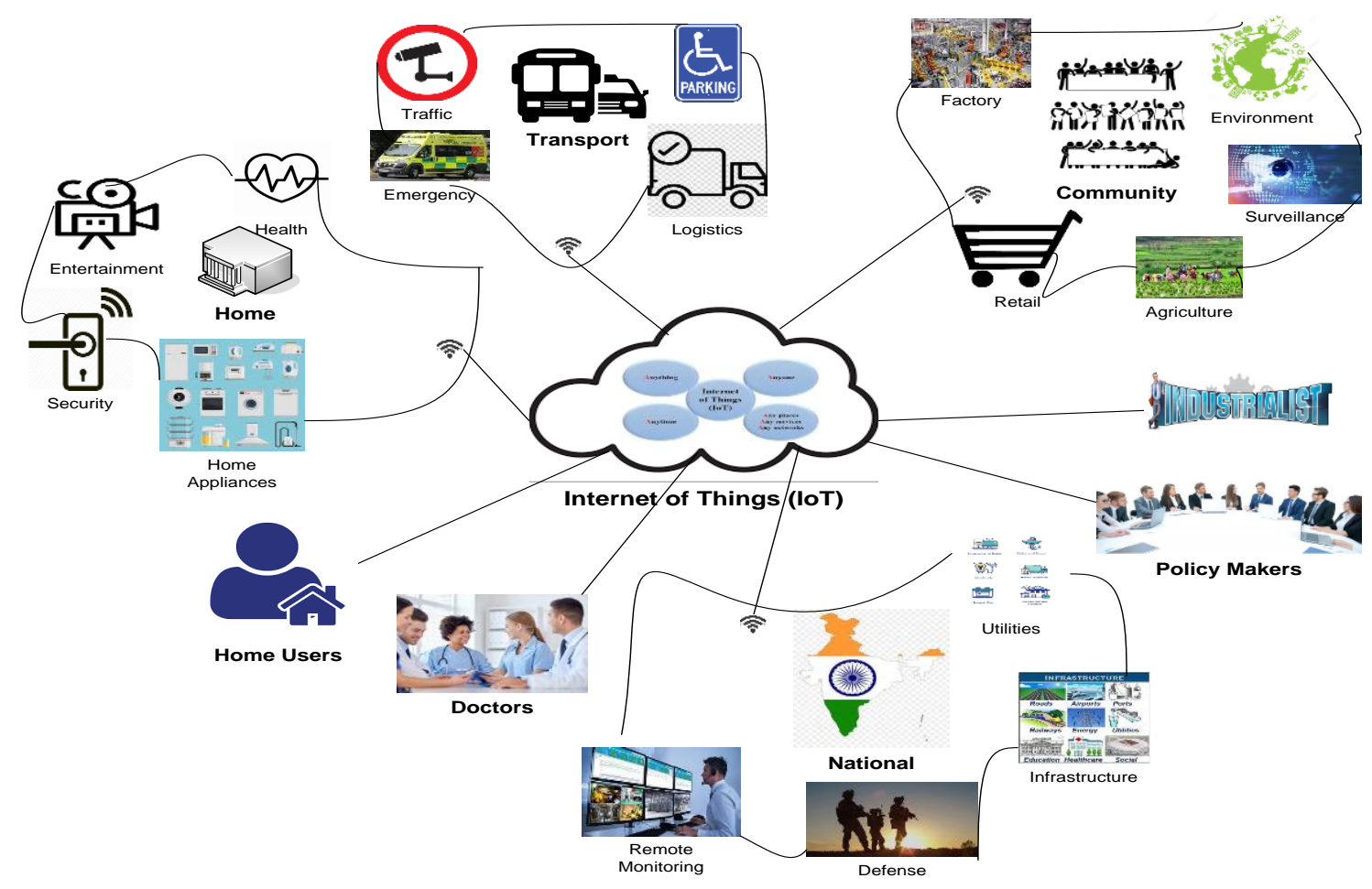

Figure 1: Quality Applications in IOT.

\section{Quality of Service in IOT Applications}

\section{Smart Cities}

The IoT gives the accompanying offices in smart cities like Efficient Water Supply with smart meters can encourage spillage identification and reduce wastage of water; Smart Traffic Management it's simpler to deal with traffic blockage with smart traffic signals, Reliable Public transportation to deal with the basic circumstance like barriers or road blocks, transportation is upset. IoT devices can give constant bits of knowledge expected to execute plans to handle such issues and have sheltered, dependable and productive open transportation. Energy Efficient Buildings IoT development is making it less complex for building vitality proficient structure structures. With the utilization of IoT Smart Management Application that controls nonstandard heating, cooling, lighting, and fire-security systems. Smart Parking utilized GPS information from PDAs and video checking can help a vehicle driver to discover a parking space. Smart Street lighting faculties or tracks the development and modifies the lighting to reduce, light up or switch off or on naturally dependent on the earth. Healthy Environment with sensors can be joined to measure the nature of the water by looking at the degree of pH, air, soil, and so on. Waste Management IoT devices like sensors can be joined to a trash compartment that assembles the information about the degree of waste in the holder [6,7, and 8]. 


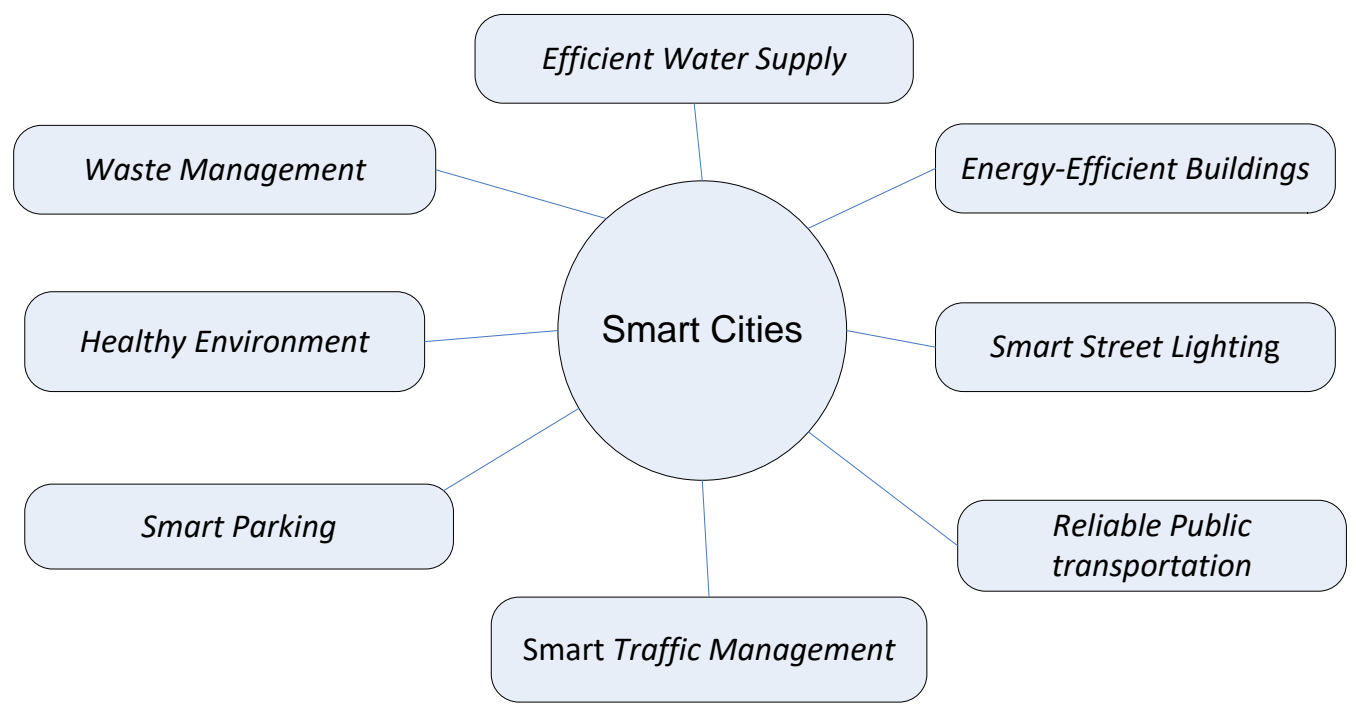

Figure 2: IOT in Smart Cities

\section{Smart Home and Buildings}

The IoT as utilized in smart home and buildings to deal with Smart Television can associate web to get to information through different applications, for example, significant video and music [10]. Smart lighting frameworks can detect while occupants are in the room and change lighting varying. A smart thermostat permits shopper to design screen and remotely sort out home temperatures and furnish the inhabitants with greatest solace and effectiveness. Smart thermostat report energy utilizes and remains client to change channels, among further things. Smart locks distinguish when inhabitants are approach and open the entryways for them. Smart surveillance cameras screen their homes when they are left or on an excursion. Pet care computerized with associated feeders. Houseplants and gardens can be watered by method of associated clocks. Kitchen appliances of numerous kinds are accessible, including smart coffee producers that can make you a new cup when your alert goes off; smart coolers used to track of termination dates, make shopping records or even make plans dependent on fixings right now close by, Household framework detects an electric flood and mood killer machines or sense water disappointments or freezing funnels and mood killer the water so there isn't a flood in your cellar [11, 12, and 13].

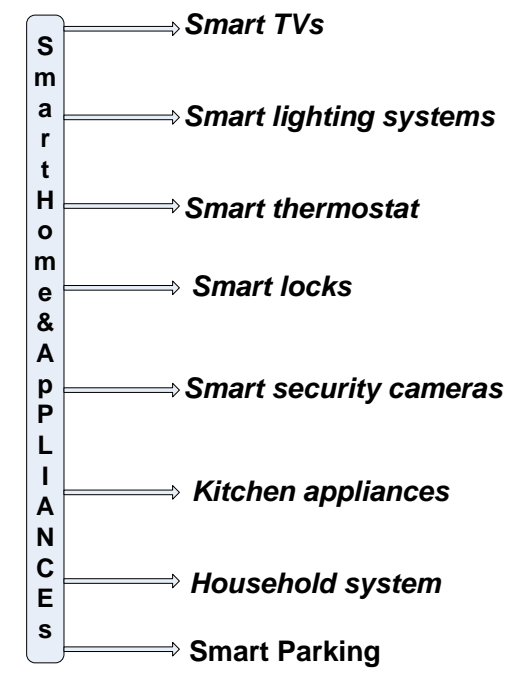

Figure 3: IOT Applications in Smart Home And Buildings. 


\section{Smart Energy and the Smart Grid}

A smart grid identified with the data and control created to have a smart energy board [17]. A smart grid that coordinate the data and correspondences advancements to the power system will empower a constant, two route correspondence among providers and purchasers, making increasingly unique association on vitality stream, which will help convey power all the more productively and sustainably[18]. The Key components of data and interchanges advances will incorporate detecting and observing advances for power streams; computerized correspondences framework to transmit information over the network; smart meters with in home presentation to educate energy utilization; coordination, control and computerization frameworks to total and procedure different information, and to make an exceptionally intuitive and dependable and can manage ordinary power changes and it will make a stride further towards utilizing a low carbon energy framework, by permitting combination between the sustainable power source and green advances, and offering numerous advantages to client in cost reserve funds through productive vitality use at home[19,20].

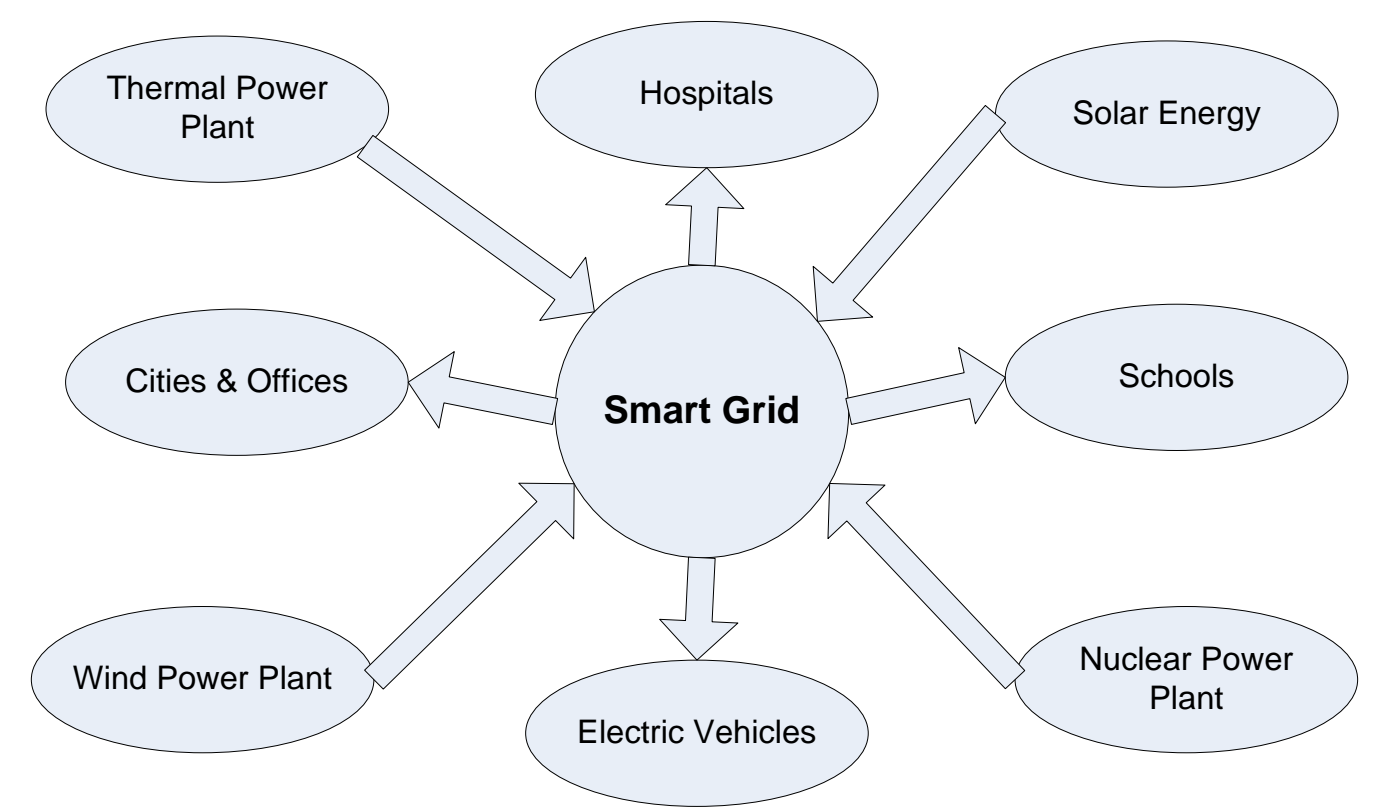

Figure 4: IOT Applications in Smart Gris and Smart Energy.

\section{Smart Health}

IoT utilized in health care for some individuals around the universes are experiencing the terrible wellbeing since they don't have prepared access to compelling wellbeing observing and might be a suspected to be as basic circumstance patients. Be that as it may, with little, ground-breaking remote arrangements associated through the IoT is presently making workable for checking to go to these patients. These arrangements can be utilized to safely catch tolerant wellbeing information from an assortment of sensors, apply complex calculations to break down the information and afterward share it through remote availability with clinical experts who can make proper wellbeing proposals.

IoT applications are used in health care for cancer treatment utilized rearrange care for the patients and care suppliers to distinguish the rising reactions and tended to rapidly and productively to improve the weight of treatment.. Smart continuous glucose monitoring (CGM) and insulin pens devices ceaselessly screen the patient blood glucose levels for a few times at a day, by taking readings at ordinary stretches. Closed-loop (automated) insulin delivery Open APS is a produces covers inhaler utilize that can be imparted to a patient's primary care physician and show whether they are utilizing it as 
frequently as is recommended Ingestible sensors follow and improve how routinely patients take their drug, just as permit the patient to have an increasingly educated discourse with their doctor about their treatment. Connected contact lenses points could figure tear glucose and give an early admonition framework to diabetics to caution them when their blood glucose levels had dropped or ascended past a specific edge. The Apple Watch application that screens sadness, used to screen their temperament and cognizance were likewise found to compare with additional top to bottom and target discernment tests and patient-revealed results. Coagulation testing is utilized to assist patients with remaining inside their helpful range and lower the danger of stroke or draining and ready to transmit results to social insurance suppliers implies less visits to the facility. the objective range.[51]

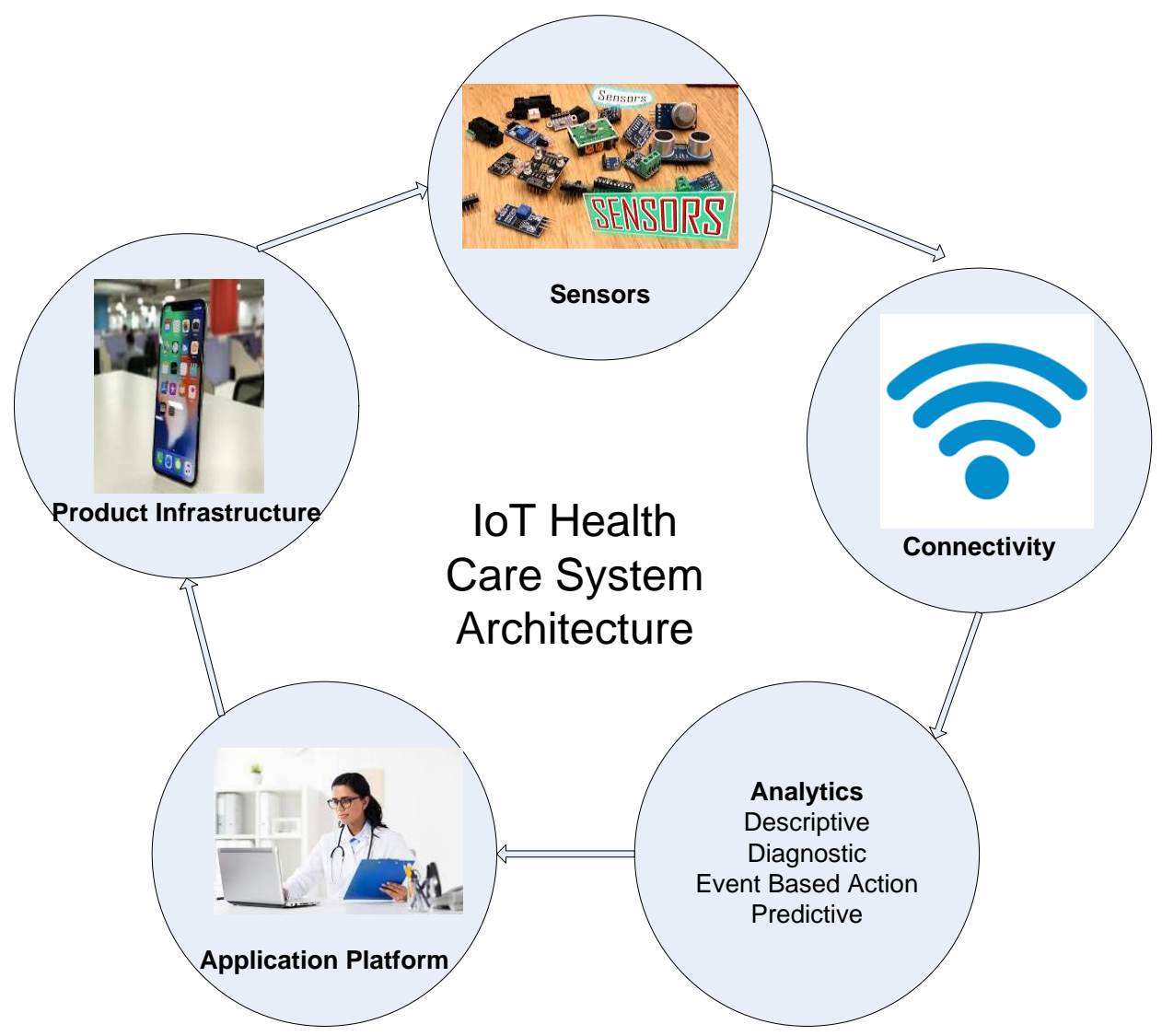

Figure 5: IOT Application in Health Care [44].

\section{Smart Transportation and Mobility}

The improvement in transportation is the important elements to show the prosperity of the nation. A road condition checking and ready application is progressively significant of IoT change application [24]. The primary idea of smart transportation and mobility is to apply the standards of publicly supporting and participatory detecting. The procedure started with client distinguished the course wishes and denoted a few focuses as pothole in the PDA's application [25]. The smart transportation is managing three primary originations as indicated in Figure 6, they are transportation systematic, transportation control, and vehicle network. The transportation expository speaks to the investigation of interest expectation and inconsistency identification. The routing of vehicles and speed control notwithstanding traffic the board are completely known as transportation control which they quite identified with the method of the vehicles network (V2X correspondence), and by and large represented by multi-innovation dispersal. 


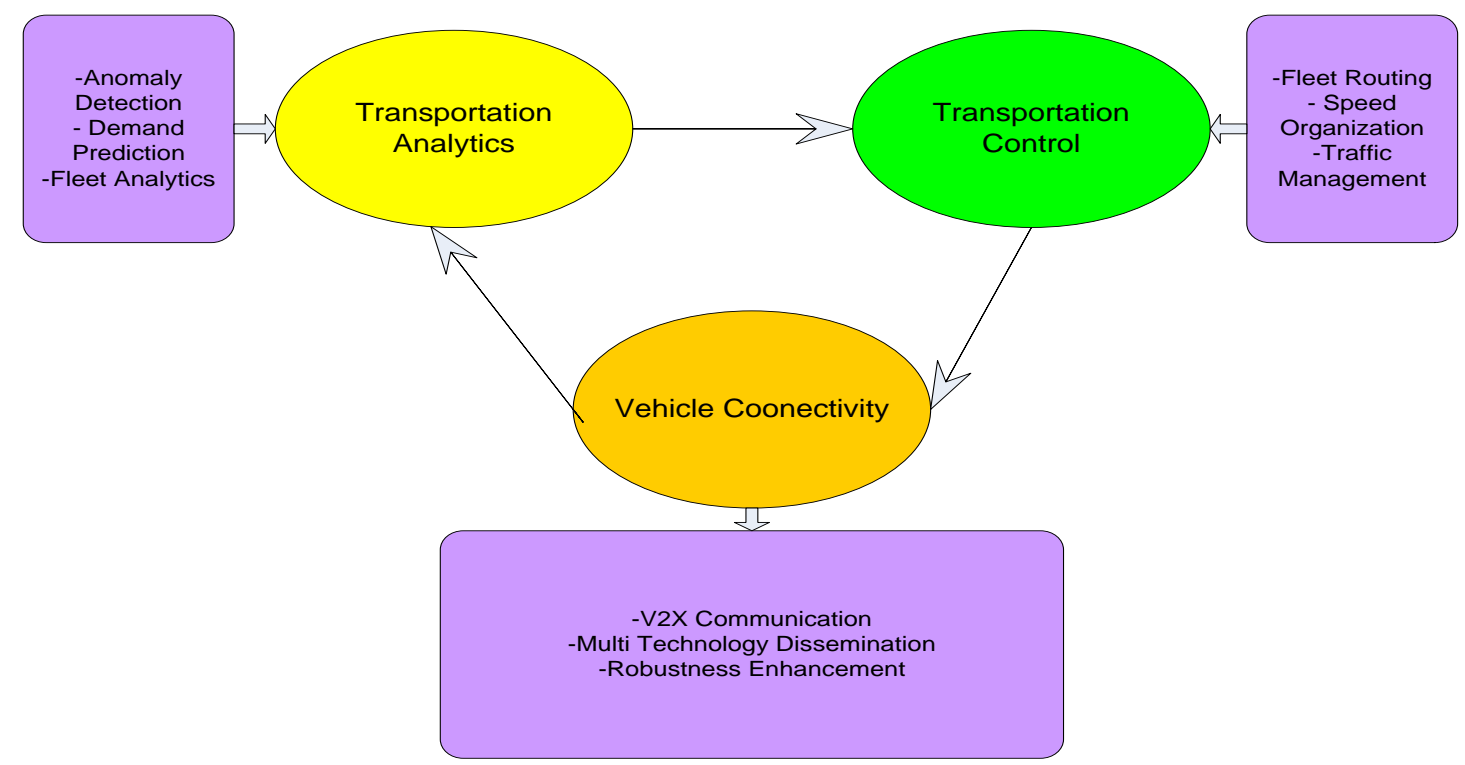

Figure 6: IOT in Smart Transportation and Mobility.

\section{Smart Factory and Manufacturing}

Smart factory included another incentive in assembling unrest by coordinate's man-made brainpower, AI, and robotization of information work and M2Mcommunication with the assembling procedure [27].The smart factory will on a very basic level change how items are created, fabricated and transported. Simultaneously it will improve laborer safety by empowering low discharges and low episode fabricating. These advances in the manner machines and different items convey and the subsequent manner by which dynamic moves from people to specialized frameworks implies that assembling becomes "more astute" [28]. new advances such ;Automation, mechanical technology, and independent versatility are all gives a methods for brilliant assembling yet M2Mcommunications empowered by the "modern" IoT will gives a full importance of smart factory and manufacturing by the method of Big Data idea which in this specific situation, refers to the scientific prospects offered by the volume and assortment of information that is created by an organized economy to enhance the mechanical procedures to suggesting less support vacation, less blackouts and much reduced energy consumption[29]. 


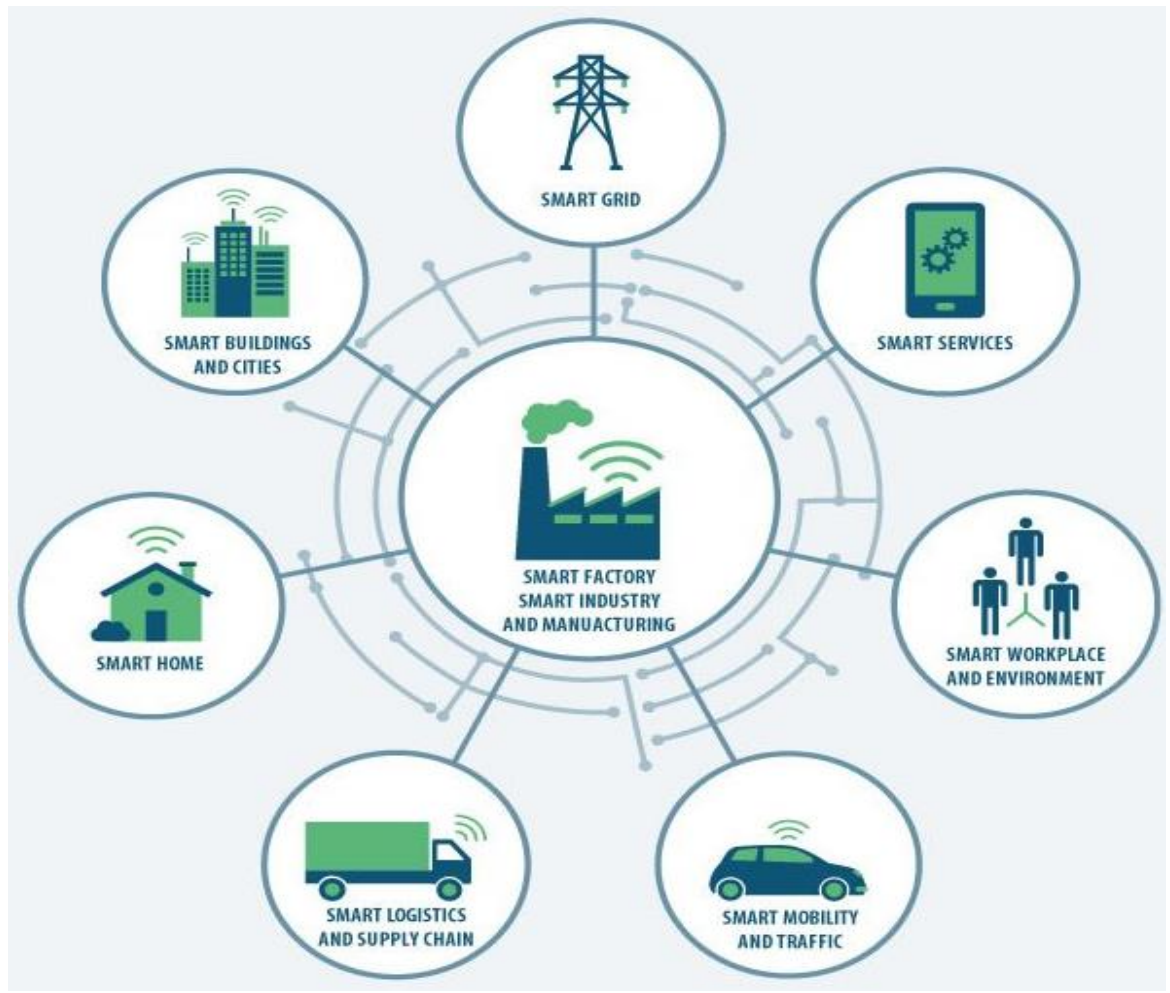

Figure 7: IOT Applications in Smart Factory and Industry.

\section{Smart Environment}

Smart condition is a significant innovation in our regular daily existence which gives numerous offices and answers for some ecological applications, for example, water and air conditioning, climate and radiation observing, squander the board, cataclysmic event, and numerous other condition markers [33]. There are numerous utilizations of IoT in condition and that can be partitioned to two principle classes ecological assets the executives, and ecological quality and insurance management[34].The assets the board identifies with every single regular asset incorporate creatures, planets and woodlands, fowls and fishes, coal, oil, land, freshwater, air and substantial metals including iron, copper and gold. Every one of these assets is probably going to reduce fundamentally or influenced by a few elements, including pollution, waste, and misuse. IoT can gives a viable method to convey between every one of these assets sensors with examinant and checking focuses to settle on suitable choices in the utilization of these sources. Inexhaustible assets incorporate daylight, and twist likewise can be overseen and detected to Ideal use in a few uses, for example, the arrangement of sustainable power sources. IoT controls the sources and their use in a number of important applications in the environment [35].

The IoT innovation can observing and dealing with the air quality by to gathering information from remote sensor over the city, and giving full-time geographic inclusion to accomplish a method of better overseeing urban traffic in significant urban communities [36]. The IoT likewise can be utilized to gauge the degrees of contamination in water so as to advise choices on water use and treatment. Squander the board is likewise one of the most significant condition issues [37]. The different kinds of waste material compound or components can dirty nature and compromise life in various manners in ground impact on creatures, people groups and plants and notwithstanding air and water. IoT gives a natural assurance implies by control the modern contamination by ongoing observing and the board frameworks incorporated to management and dynamic systems to lessen squander, and improved condition [38]. 
Radiation obviously is one of the most major issues confronting environment of the earth. The radiation delivered by atomic force plants and a few enterprises adversely influenced safety of a natural and human wellbeing, creature and horticultural profitability [40]. For atomic radiations, radiation control IoT sensor arrange can consistent observing of radiation levels around atomic offices for spillage discovery and engendering anticipation [41]. The sensors organize shaped by remote connection many sensor gadgets in regions environmental factors atomic force plants with closes nearness to urban communities [42].

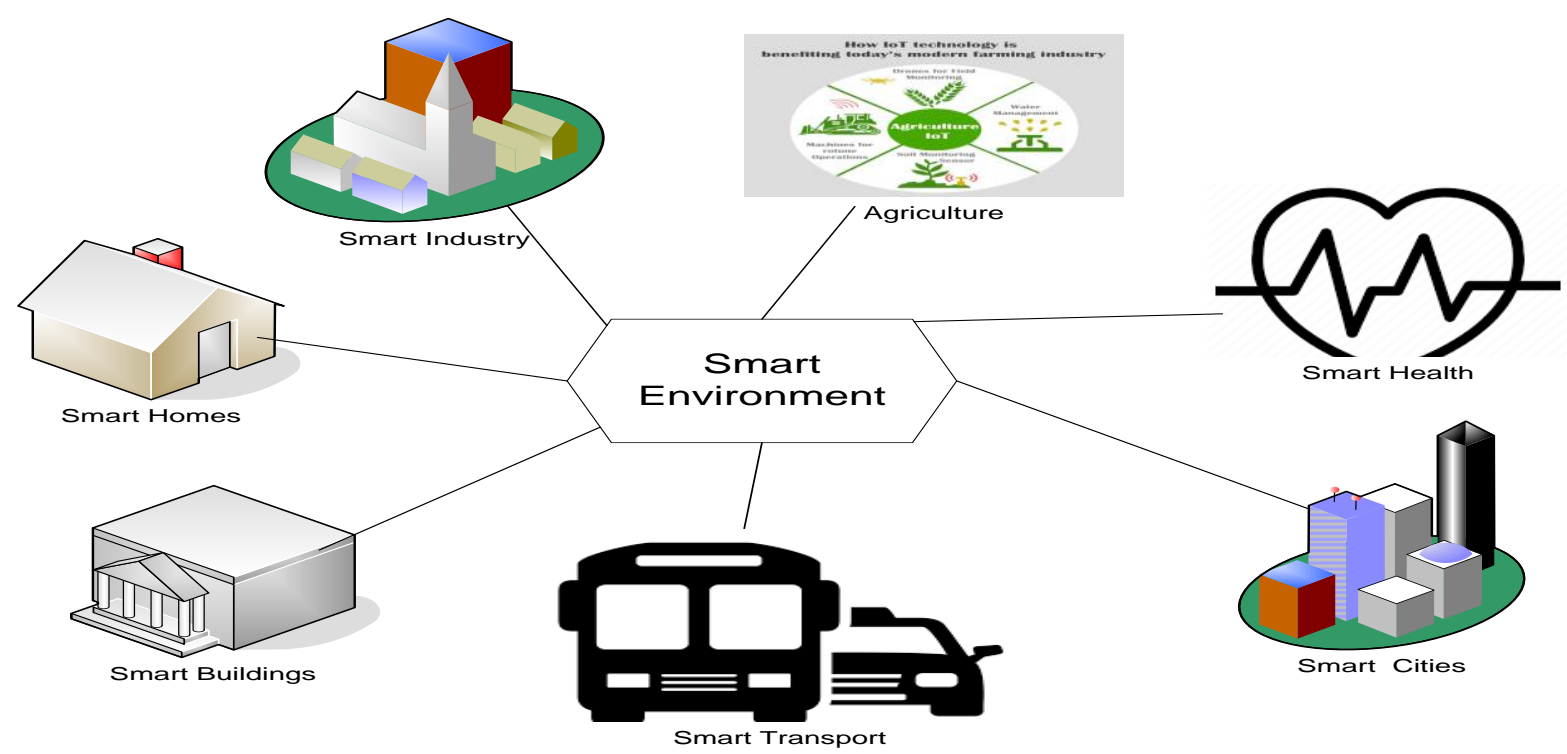

Figure 8: IOT Applications in Smart Transport.

Comparison of Quality of Service in Issues in Various IOT Applications

Table 1: Network Characteristics of IOT Technologies

\begin{tabular}{|c|c|c|c|c|c|c|}
\hline Technology & Frequency & $\begin{array}{l}\text { Limit / } \\
\text { Range } \\
\end{array}$ & Data Speed & $\begin{array}{c}\text { Battery Life } \\
\text { Span }\end{array}$ & Topology & $\begin{array}{c}\text { Governing } \\
\text { Body }\end{array}$ \\
\hline RFID & 1Giga Hertz & $\begin{array}{l}1 \text { centi } \\
\text { metre-100 } \\
\text { meter }\end{array}$ & $\begin{array}{l}\text { 1-100 kilo bit } \\
\text { per second }\end{array}$ & 3-5 Years & $\mathrm{P} 2 \mathrm{P}$ & Single Body \\
\hline NFC & $\begin{array}{l}\text { 13.56 Mega } \\
\text { Hertz }\end{array}$ & 0.2 meter & $\begin{array}{l}424 \text { kilo bit } \\
\text { per second }\end{array}$ & 3-5 Years & $\mathrm{P} 2 \mathrm{P}$ & ISO/IEC \\
\hline BLE & $\begin{array}{l}\text { 2.4 Giga } \\
\text { Hertz }\end{array}$ & $\begin{array}{l}10-100 \\
\text { meter }\end{array}$ & $\begin{array}{l}1 \text { mega bit } \\
\text { per second }\end{array}$ & 1 Years & $\begin{array}{l}\text { P2P/Star/Tree } \\
\text { /Mesh }\end{array}$ & Bluetooth SIG \\
\hline Ant & $\begin{array}{l}\text { 2.4 Giga } \\
\text { Hertz }\end{array}$ & 30meter & $\begin{array}{l}1 \text { mega bit } \\
\text { per second }\end{array}$ & 1 Years & $\begin{array}{l}\text { P2P/Star/Tree } \\
\text { /Mesh }\end{array}$ & Gamin \\
\hline EnOcean & $\begin{array}{l}\text { Sub-1 Giga } \\
\text { Hertz }\end{array}$ & $\begin{array}{l}30- \\
300 \text { meter }\end{array}$ & $\begin{array}{l}125 \text { kilo bit } \\
\text { per second }\end{array}$ & $\begin{array}{l}\text { Months to } \\
\text { Years }\end{array}$ & Mesh & $\begin{array}{l}\text { EnOcean } \\
\text { Alliance }\end{array}$ \\
\hline Z-Wave & $\begin{array}{l}\text { Sub-1 Giga } \\
\text { Hertz }\end{array}$ & $\begin{array}{l}40- \\
200 \text { meter }\end{array}$ & $\begin{array}{l}100 \text { kilo bit } \\
\text { per second s }\end{array}$ & $\begin{array}{l}\text { Months to } \\
\text { Years }\end{array}$ & Mesh & Z-wave Alliance \\
\hline Insteon & $\begin{array}{l}\text { sub-1 Giga } \\
\text { Hertz }\end{array}$ & $\begin{array}{l}30-50 \\
\text { meter }\end{array}$ & $\begin{array}{l}37.5 \text { kilo bit } \\
\text { per second }\end{array}$ & $\begin{array}{l}\text { Months to } \\
\text { Years }\end{array}$ & Mesh & Smart labs \\
\hline ZigBee & $\begin{array}{l}\text { sub-1Giga } \\
\text { Hertz, } 2.4 \\
\text { Giga Hertz }\end{array}$ & $\begin{array}{l}10- \\
100 \text { meter }\end{array}$ & $\begin{array}{l}250 \text { kilo bit } \\
\text { per second }\end{array}$ & $\begin{array}{l}\text { Months to } \\
\text { Years }\end{array}$ & $\begin{array}{l}\text { Star / Mesh / } \\
\text { Tree }\end{array}$ & ZigBee Alliance \\
\hline MiWi & $\begin{array}{l}\text { sub-1Giga } \\
\text { Hertz, } 2.4 \\
\text { Giga Hertz }\end{array}$ & $\begin{array}{l}10- \\
100 \text { meter }\end{array}$ & $\begin{array}{l}250 \text { kilo bit } \\
\text { per second }\end{array}$ & $\begin{array}{l}\text { Months to } \\
\text { Years }\end{array}$ & $\begin{array}{l}\text { Star / Mesh / } \\
\text { Tree }\end{array}$ & $\begin{array}{l}\text { Microchip } \\
\text { Technology }\end{array}$ \\
\hline
\end{tabular}




\begin{tabular}{|c|c|c|c|c|c|c|}
\hline DigiMesh & $\begin{array}{l}\text { sub-1Giga } \\
\text { Hertz, } 2.4 \\
\text { Giga Hertz } \\
\end{array}$ & $\begin{array}{l}10- \\
100 \text { meter }\end{array}$ & $\begin{array}{l}250 \text { kilo bit } \\
\text { per second }\end{array}$ & $\begin{array}{l}\text { Months to } \\
\text { Years }\end{array}$ & P2P Mesh & $\begin{array}{l}\text { Digi } \\
\text { International }\end{array}$ \\
\hline $\begin{array}{l}\text { Wireless } \\
\text { HART }\end{array}$ & $\begin{array}{l}\text { sub-1Giga } \\
\text { Hertz, } 2.4 \\
\text { Giga Hertz } \\
\end{array}$ & $\begin{array}{l}10- \\
100 \text { meter }\end{array}$ & $\begin{array}{l}250 \text { kilo bit } \\
\text { per second }\end{array}$ & Years & Mesh & $\begin{array}{l}\text { HART } \\
\text { Communication }\end{array}$ \\
\hline Thread & $\begin{array}{l}\text { sub-1 Giga } \\
\text { Hertz, } 2.4 \\
\text { Giga Hertz }\end{array}$ & $\begin{array}{l}10- \\
100 \text { meter }\end{array}$ & $\begin{array}{l}250 \text { kilo bit } \\
\text { per second }\end{array}$ & $\begin{array}{l}\text { Months to } \\
\text { Years }\end{array}$ & $\begin{array}{l}\text { Star / Mesh / } \\
\text { Tree }\end{array}$ & $\begin{array}{l}\text { Thread Group } \\
\text { Alliance }\end{array}$ \\
\hline 6LowPAN & $\begin{array}{l}\text { sub-1 Giga } \\
\text { Hertz, } 2.4 \\
\text { Giga Hertz }\end{array}$ & $\begin{array}{l}10- \\
100 \text { meter }\end{array}$ & $\begin{array}{l}250 \text { kilo bit } \\
\text { per second }\end{array}$ & $\begin{array}{l}\text { Months to } \\
\text { Years }\end{array}$ & $\begin{array}{l}\text { Star / Mesh / } \\
\text { Tree }\end{array}$ & IETF \\
\hline Wi-Fi & $\begin{array}{l}2.4 \text { Giga } \\
\text { Hertz, } 5 \text { sub- } \\
1 \text { Giga Hertz } \\
\text { (Wi-Fi } \\
\text { HaLow) }\end{array}$ & $\begin{array}{l}\text { 100meter } \\
-1 \text { kilo } \\
\text { meter }\end{array}$ & $\begin{array}{l}1 \text { mega bit } \\
\text { per second to } \\
\text { Giga bit per } \\
\text { second }\end{array}$ & $\begin{array}{l}\text { Days to } \\
\text { Month }\end{array}$ & Star & Wi-Fi Alliance \\
\hline NB-IoT & $\begin{array}{l}450 \text { Mega } \\
\text { Hertz-3.5 } \\
\text { Giga Hertz }\end{array}$ & $\begin{array}{l}10-15 \\
\text { kilo meter }\end{array}$ & $\begin{array}{l}250 \text { kilo bit } \\
\text { per second }\end{array}$ & $10+$ years & Star & 3GPP \\
\hline Emtc & $\begin{array}{l}450 \text { Mega } \\
\text { Hertz-3.5 } \\
\text { Giga Hertz }\end{array}$ & $\begin{array}{l}10-15 \\
\text { kilo meter }\end{array}$ & $\begin{array}{l}1 \text { mega bit } \\
\text { per second }\end{array}$ & $10+$ years & Star & 3GPP \\
\hline $\begin{array}{l}\text { EC-GSM- } \\
\text { IoT }\end{array}$ & $\begin{array}{l}\text { 90- } 850 \text { Mega } \\
\text { Hertz }\end{array}$ & $\begin{array}{l}10-15 \\
\text { kilo meter }\end{array}$ & $\begin{array}{l}70-240 \text { kilo } \\
\text { bit per second }\end{array}$ & $10+$ years & Star & 3GPP \\
\hline LoRaWAN & $\begin{array}{l}\text { sub-1 Giga } \\
\text { Hertz }\end{array}$ & $\begin{array}{l}10-15 \\
\text { kilo meter }\end{array}$ & $\begin{array}{l}50 \text { kilo bit per } \\
\text { second }\end{array}$ & $10+$ years & Star of stars & LoRa Alliance \\
\hline $\begin{array}{l}\text { Symphony } \\
\text { Link }\end{array}$ & $\begin{array}{l}\text { sub-1 Giga } \\
\text { Hertz }\end{array}$ & $\begin{array}{l}10-15 \\
\text { kilo meter }\end{array}$ & $\begin{array}{l}50 \text { kilo bit per } \\
\text { second }\end{array}$ & $10+$ years & Star & Link Labs \\
\hline Weightless & $\begin{array}{l}\text { sub-1 Giga } \\
\text { Hertz }\end{array}$ & $\begin{array}{l}2-5 \text { kilo } \\
\text { meter }\end{array}$ & $\begin{array}{l}10 \text { kilo bit per } \\
\text { second- } 10 \\
\text { mega bit per } \\
\text { second }\end{array}$ & $3-10$ years & Star & Weightless SIG \\
\hline SIGFOX & $\begin{array}{l}\text { sub-1 Giga } \\
\text { Hertz }\end{array}$ & $\begin{array}{l}10-15 \\
\text { kilo meter }\end{array}$ & $\begin{array}{l}100 \text { kilo bit } \\
\text { per second }\end{array}$ & $10+$ years & Star & Sigfox \\
\hline DASH7 & $\begin{array}{l}\text { sub-1 Giga } \\
\text { Hertz }\end{array}$ & $\begin{array}{l}2-5 \text { kilo } \\
\text { meter }\end{array}$ & $\begin{array}{l}167 \text { kilo bit } \\
\text { per second }\end{array}$ & $10+$ years & Star/Tree & Dash 7 Alliance \\
\hline
\end{tabular}

The tables clarify the network characteristics like frequency band, range, data rate, battery life, topology and governing body of the various technologies.

\section{QoS issues of IoT Applications}

Table 2: Traffic Characteristics of IOT Applications[47]

\begin{tabular}{|c|c|c|c|}
\hline Application & Service & Traffic Rate & Delay Variance \\
\hline \multirow{5}{*}{ 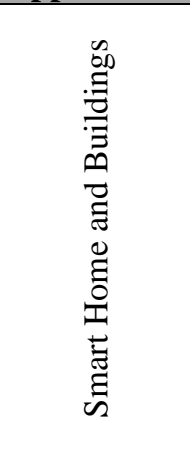 } & $\begin{array}{l}\text { Building condition } \\
\text { monitoring(excluding } \\
\text { anomaly detection) }\end{array}$ & $\begin{array}{l}\text { regular, } 1 \text { message every hour } \\
\text { per device }\end{array}$ & $\begin{array}{l}\text { low, tolerable delay } 1 \\
\text { minutes }\end{array}$ \\
\hline & Anomaly detection & irregular, rare & $\begin{array}{l}\text { high, tolerable delay } 3 \\
\text { seconds }\end{array}$ \\
\hline & Lighting control & irregular, rare & $\begin{array}{l}\text { high, tolerable delay } 3 \\
\text { seconds }\end{array}$ \\
\hline & Indoor climate control & $\begin{array}{l}\text { regular, } 1 \text { message every } 15 \\
\text { minutes per device }\end{array}$ & $\begin{array}{l}\text { high, tolerable delay } 5 \\
\text { seconds }\end{array}$ \\
\hline & Smart appliances & irregular, rare & $\begin{array}{l}\text { high, tolerable delay } 3 \\
\text { seconds }\end{array}$ \\
\hline
\end{tabular}




\begin{tabular}{|c|c|c|c|}
\hline & Energy and water use & irregular, rare & $\begin{array}{l}\text { high, tolerable delay } 3 \\
\text { seconds }\end{array}$ \\
\hline \multirow{4}{*}{ 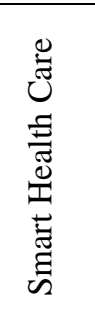 } & $\begin{array}{l}\text { Chronic disease } \\
\text { management }\end{array}$ & $\begin{array}{l}\text { regular, frequency based on } \\
\text { the type of disease }\end{array}$ & $\begin{array}{l}\text { high, tolerable delay based } \\
\text { on the type of disease }\end{array}$ \\
\hline & $\begin{array}{l}\text { Personal condition } \\
\text { monitoring }\end{array}$ & $\begin{array}{l}\text { regular, } 1 \text { message every } 10 \\
\text { seconds per device }\end{array}$ & $\begin{array}{l}\text { high, tolerable delay } 5 \\
\text { seconds }\end{array}$ \\
\hline & Personal assistance & $\begin{array}{l}\text { regular, } 1 \text { message every } 10 \\
\text { seconds per device }\end{array}$ & $\begin{array}{l}\text { high, tolerable delay } 3 \\
\text { seconds }\end{array}$ \\
\hline & Patients surveillance & $\begin{array}{l}\text { regular, } 1 \text { message every } 10 \\
\text { seconds per device }\end{array}$ & $\begin{array}{l}\text { high, tolerable delay } 3 \\
\text { seconds }\end{array}$ \\
\hline \multirow{6}{*}{ 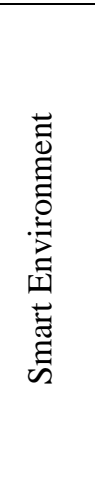 } & Forest fire detection & irregular, rare & $\begin{array}{l}\text { medium, tolerable delay } 15 \\
\text { Seconds }\end{array}$ \\
\hline & Earthquake detection & irregular, rare & $\begin{array}{l}\text { medium, tolerable delay } 5 \\
\text { Seconds }\end{array}$ \\
\hline & Tsunami detection & irregular, rare & $\begin{array}{l}\text { medium, tolerable delay } 5 \\
\text { Seconds }\end{array}$ \\
\hline & $\begin{array}{l}\text { Landslide and } \\
\text { avalanche Detection }\end{array}$ & irregular, rare & $\begin{array}{l}\text { high, tolerable delay } 5 \\
\text { seconds }\end{array}$ \\
\hline & $\begin{array}{l}\text { Air pollution } \\
\text { monitoring }\end{array}$ & $\begin{array}{l}\text { regular, } 1 \text { message every } 15 \\
\text { minutes per device }\end{array}$ & $\begin{array}{l}\text { medium, tolerable delay } 15 \\
\text { Seconds }\end{array}$ \\
\hline & Wildlife tracking & $\begin{array}{l}\text { regular, } 1 \text { message every } 30 \\
\text { minutes per device }\end{array}$ & $\begin{array}{l}\text { low, tolerable delay a few } \\
\text { hours }\end{array}$ \\
\hline \multirow{7}{*}{ 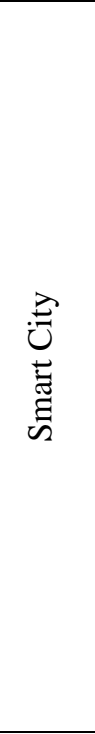 } & $\begin{array}{l}\text { City energy and water } \\
\text { consumption } \\
\text { monitoring }\end{array}$ & $\begin{array}{l}\text { regular, } 1 \text { message every } 10 \\
\text { minutes per device }\end{array}$ & $\begin{array}{l}\text { low, tolerable delay } 1 \\
\text { minutes }\end{array}$ \\
\hline & Lightning control & irregular, rare & $\begin{array}{l}\text { medium, tolerable delay } 15 \\
\text { seconds }\end{array}$ \\
\hline & Parking tracking & irregular, rare & $\begin{array}{l}\text { medium, tolerable delay } 10 \\
\text { seconds }\end{array}$ \\
\hline & Traffic management & $\begin{array}{l}\text { regular, } 1 \text { message every } 10 \\
\text { minutes per device; irregular } \\
\text { for alarms }\end{array}$ & $\begin{array}{l}\text { medium, tolerable delay } 15 \\
\text { seconds; high for alarms }\end{array}$ \\
\hline & Waste management & irregular, rare & $\begin{array}{l}\text { medium, tolerable delay } 30 \\
\text { seconds }\end{array}$ \\
\hline & $\begin{array}{l}\text { Urban conditions } \\
\text { monitoring }\end{array}$ & $\begin{array}{l}\text { regular, } 1 \text { message every } 15 \\
\text { minutes per device; irregular } \\
\text { for alarms }\end{array}$ & $\begin{array}{l}\text { medium, tolerable delay } 30 \\
\text { seconds; high for alarms }\end{array}$ \\
\hline & $\begin{array}{l}\text { Structural health } \\
\text { monitoring }\end{array}$ & $\begin{array}{l}\text { regular, } 1 \text { message every } 15 \\
\text { minutes per device; irregular } \\
\text { for alarms }\end{array}$ & $\begin{array}{l}\text { medium, tolerable delay } 30 \\
\text { seconds; high for alarms }\end{array}$ \\
\hline \multirow{3}{*}{ 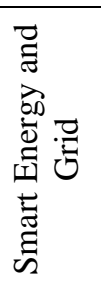 } & Smart metering & $\begin{array}{l}\text { regular, } 1 \text { message every } 15 \\
\text { minutes per device }\end{array}$ & $\begin{array}{l}\text { medium, tolerable delay } 15 \\
\text { seconds }\end{array}$ \\
\hline & Asset management & $\begin{array}{l}\text { regular, } 1 \text { message every } 15 \\
\text { minutes per device }\end{array}$ & $\begin{array}{l}\text { medium, tolerable delay } 15 \\
\text { seconds }\end{array}$ \\
\hline & Outage detection & Irregular, rare & $\begin{array}{l}\text { high, tolerable delay near } \\
\text { real time }\end{array}$ \\
\hline \multirow{4}{*}{ 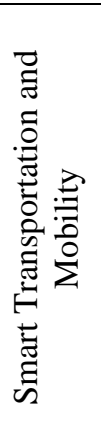 } & Vehicle automation & $\begin{array}{l}\text { regular, } 1 \text { message every } 24 \\
\text { hours per vehicle, irregular } \\
\text { and frequent in vehicle-to- } \\
\text { vehicle (V2V) } \\
\text { communication }\end{array}$ & $\begin{array}{l}\text { low, tolerable delay } 1 \\
\text { minutes; } \\
\text { high for } \mathrm{V} 2 \mathrm{~V} \text {, tolerable de- } \\
\text { lay near real-time }\end{array}$ \\
\hline & $\begin{array}{l}\text { Vehicle localization } \\
\text { and } \\
\text { Monitoring }\end{array}$ & $\begin{array}{l}\text { regular, } 1 \text { message every } 30 \\
\text { seconds per vehicle }\end{array}$ & $\begin{array}{l}\text { medium, tolerable delay } 10 \\
\text { seconds }\end{array}$ \\
\hline & $\begin{array}{l}\text { Quality of shipment } \\
\text { conditions monitoring }\end{array}$ & $\begin{array}{l}\text { regular, } 1 \text { message every } 15 \\
\text { minutes per device }\end{array}$ & $\begin{array}{l}\text { medium, tolerable delay } 15 \\
\text { seconds }\end{array}$ \\
\hline & Dynamic traffic lights & regular, 1 message every 1 & high, tolerable delay 5 \\
\hline
\end{tabular}




\begin{tabular}{|c|c|c|c|}
\hline & control & $\begin{array}{l}\text { minutes } \\
\text { per device }\end{array}$ & seconds \\
\hline & $\begin{array}{l}\text { Road condition } \\
\text { monitoring }\end{array}$ & irregular, rare & $\begin{array}{l}\text { medium, tolerable delay } 30 \\
\text { seconds }\end{array}$ \\
\hline \multirow{5}{*}{ 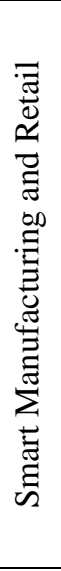 } & Production line & $\begin{array}{l}\text { regular, frequency varies; ir- } \\
\text { regular for alarms }\end{array}$ & $\begin{array}{l}\text { usually high, tolerable } \\
\text { delay a few seconds; high } \\
\text { for alarms }\end{array}$ \\
\hline & Inventory tracking & irregular, rare & $\begin{array}{l}\text { medium, tolerable delay } 10 \\
\text { Seconds }\end{array}$ \\
\hline & Indoor localization & irregular, rare & $\begin{array}{l}\text { high, tolerable delay } 5 \\
\text { seconds }\end{array}$ \\
\hline & $\begin{array}{l}\text { Environment } \\
\text { monitoring }\end{array}$ & $\begin{array}{l}\text { regular, } 1 \text { message every } 10 \\
\text { minutes per device; irregular } \\
\text { for alarms }\end{array}$ & $\begin{array}{l}\text { medium, tolerable delay } 15 \\
\text { seconds; high for alarms }\end{array}$ \\
\hline & $\begin{array}{l}\text { Maintenance and repair } \\
\text { Optimization }\end{array}$ & $\begin{array}{l}\text { regular for condition re-ports, } \\
1 \text { message every } 10 \text { minutes } \\
\text { per device; irregular for } \\
\text { alarms }\end{array}$ & $\begin{array}{l}\text { medium, tolerable delay } 15 \\
\text { seconds; high for alarms }\end{array}$ \\
\hline \multirow{4}{*}{ 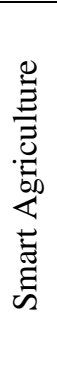 } & Irrigation & $\begin{array}{l}\text { regular, } 1 \text { message every } 6 \\
\text { hours per device }\end{array}$ & $\begin{array}{l}\text { low, tolerable delay } 1 \\
\text { minutes }\end{array}$ \\
\hline & Fertilization & $\begin{array}{l}\text { regular, } 1 \text { message every } 6 \\
\text { hours per device }\end{array}$ & $\begin{array}{l}\text { low, tolerable delay } 1 \\
\text { minutes }\end{array}$ \\
\hline & Pest control & $\begin{array}{l}\text { regular, } 1 \text { message every } 6 \\
\text { hours per device }\end{array}$ & low, tolerable delay $1 \mathrm{mi}$ \\
\hline & Animal monitoring & $\begin{array}{l}\text { regular, } 1 \text { message every } 6 \\
\text { hours per device; can be } \\
\text { irregular }\end{array}$ & $\begin{array}{l}\text { low, tolerable delay } 1 \\
\text { minutes; } \\
\text { high for alarms }\end{array}$ \\
\hline
\end{tabular}

\section{Evaluation of Traffic Rate and Delay Variance}

In the past segment, we characterized traffic qualities of IoT application services. To accomplish our goal, for example to decide with high exactness the requests on systems characterized by different IoT application situations, we recognized and examined the most regular administrations for each area, test ined the system setups proposed by different analysts, and joined the data with our exploration advantages to determine the results.

Together, we depicted 40 services from eight applications as appeared in Table.During the procedure; we experienced arrangements that were tending to a similar issue with marginally various designs, contingent upon the particular execution and creators' observation. We discover these distinctions totally adequate as there is no all inclusive response to every conceivable circumstance. The significant actuality is that the basic angles continued as before in all cases. In this way, our characterized traffic qualities can be viewed as the reference direct for proposing progressively effective arrangements and understanding the requests on organize advances from the IoT point of view. 


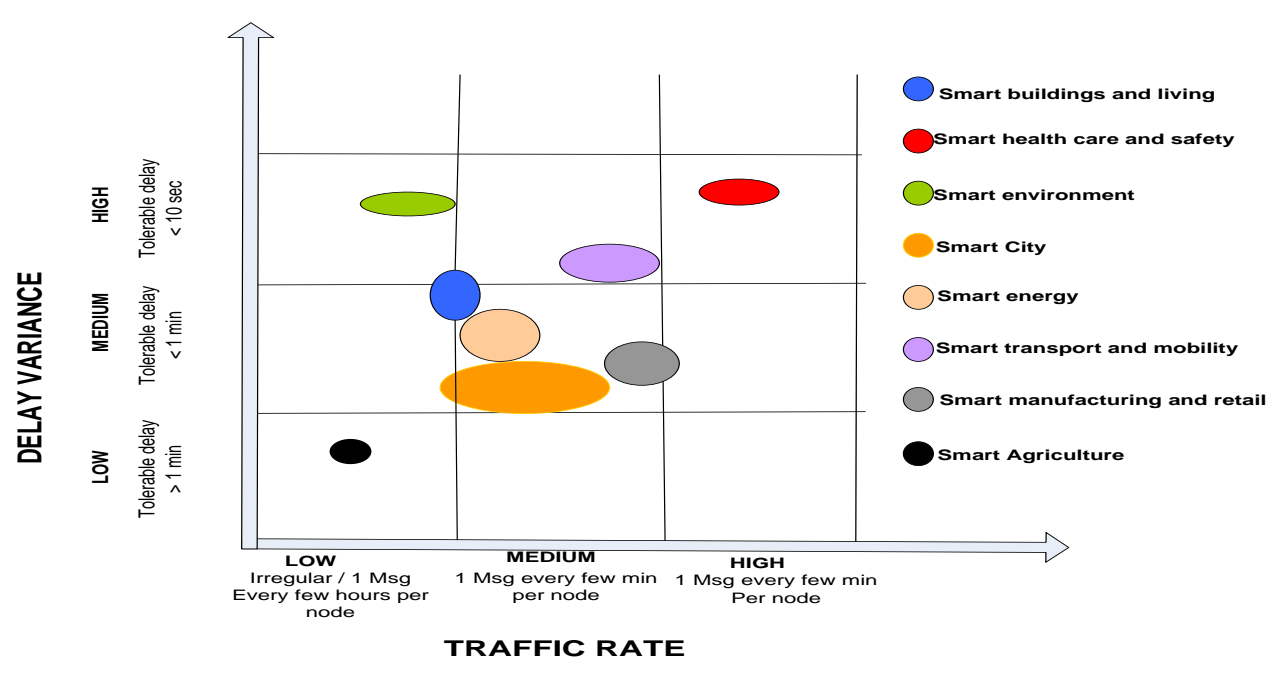

Figure 9: Relationship Between Traffic Rate and Delay Variance in IOT Applications.

The connection between network traffic rate and network delay variance represented in Fig. 9. These qualities have been talked about for each help in IoT application areas, however no immediate correlation has been made between them. In any case, as appeared in Fig. 9, the connection is significant. In the dominant part cases, the network traffic rate additionally implies the system network delay variance, particularly concerning decent deferral. The normal model is the brilliant social insurance, where even minutes or changes in conditions can bring about a basic circumstance and along these lines administrations need to refresh information consistently and dependably.

In actuality, the network traffic rate and network delay variance are not equivalent each time in keen condition. This area doesn't send information all the time, however once an uncommon occasion is recognized, the framework should quickly trigger the alarm. Moreover, we might want to feature the issues and versatile model going to actualize to decrease the traffic rate and delay variance (Jitter) in different administrations of IoT applications. These investigations are fundamental for understanding the particular prerequisites of the IoT areas so we can plan more financially smart arrangements.

\section{Preventive Model on Qos Issues in IOT Applications}

\section{Overview of Preventive Model}

The proposed preventive model on Quality of service issues in IoT application consolidates three layers specifically physical, system (or) network and data (or) information. The essential objective is guarantee that to decrease real time traffic with less time prerequisites shows up to the end client with low postponement with unwavering quality necessities accomplishes a high throughput and high packet delivery ratio. 


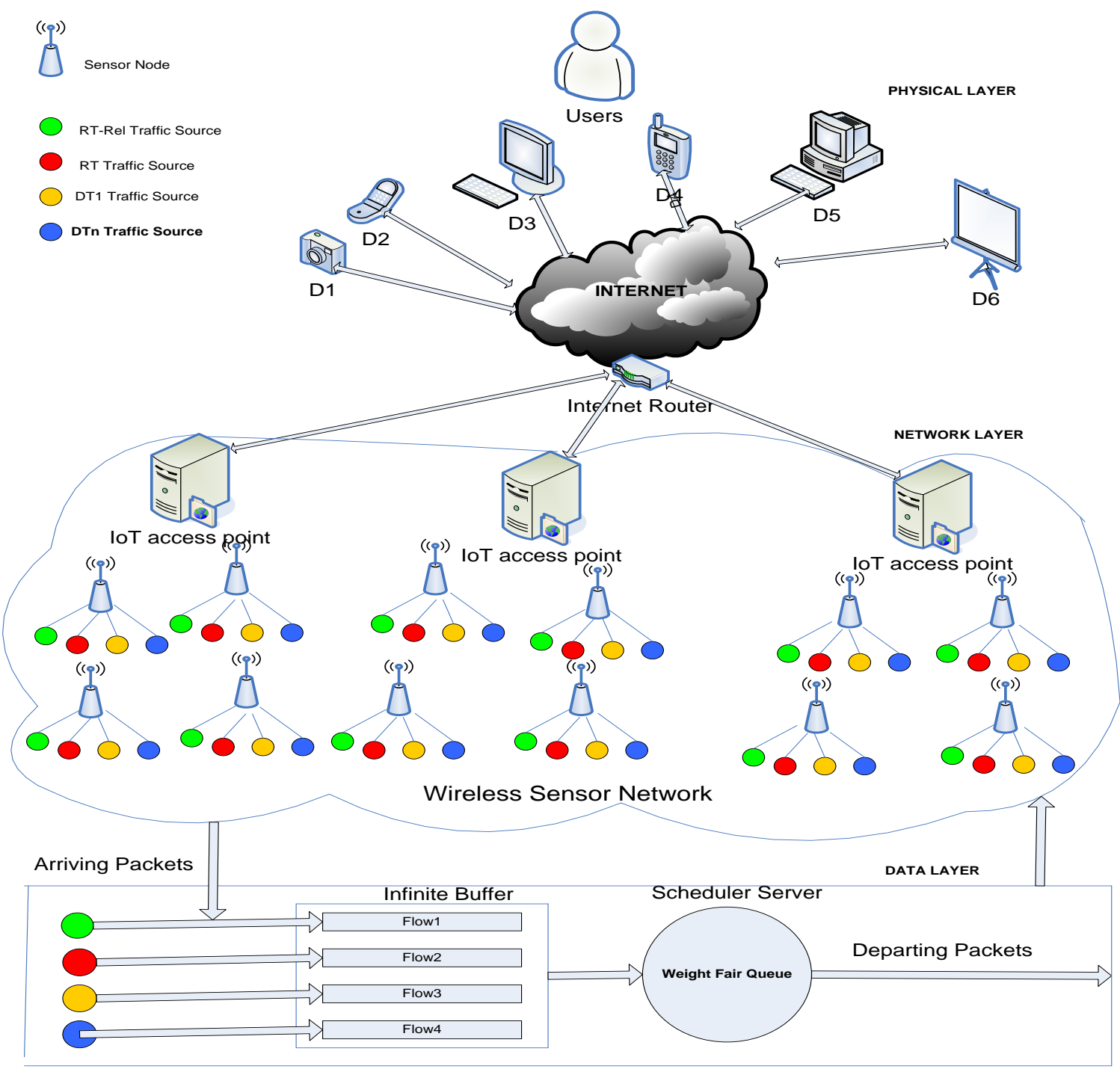

Figure 10: Preventive Model on Quality of Service Issues in IOT Application[47].

\section{A. Physical Layer}

It is accepted that the IoT application running over the heterogeneous traffic, information are produced routinely. Sensor hub produces a persistent progression of information at standard spans, for a considerable length of time a lot of online concurrent traffic the upstream way. IoT bargains trillion sensors, billion devices and million applications are producing and moving with utilization of Wireless Sensor Network (WSN) day by day. These sensors are making real time traffic, real time tolerant traffic, delay time traffic and delay tolerant traffic.

\section{B. Network (or) System Layer}

In network layer the sensor nodes have two way communications with the IoT access point. However no sensor-to-sensor communication is assumed. Each node generates packets of different types, depicted by different colors in the figure. The IoT access point, which acts as the IoT access point to the sensor network, relays the received packets to users through internet. The IoT access point may also act as cluster head for a particular physical space, hence the assumption of a multiple access point networks. The figure shows in comminutes traffic flows. Once they arrive at the IoT access point, they are allocated to the buffer queues. Here the main works of network layer differentiate the data based on its nature like RT-Rel 
traffic source, RT traffic source, DT1 traffic source and DTn traffic source.

\section{Data (or) Information Layer}

It depicts queuing system for updating the buffer for data packets for transmission at the IoT access point. Upon arrival at the IoT access point at the IoT access point, the data will be allocated to different buffer queues based on its nature. To discriminate the traffic classes from each other, we assume that each sensor adds a traffic class identifier to its local sensor packets and put them into proper queues. This identifier represents the traffic class of each packet. A buffer is allocated for each traffic class. Hence increasing number of traffic classes imposes a greater number of required buffers as well as hardware requirements.

The figure illustrates a WFQ queuing system. Each class is served on a fixed weight to the related queue. The weight is allotted according to the traffic's QoS requirement, such as delay dead line. For instance let's consider a four class's job system with a finite buffer size $\mathrm{K}$ [60]. This means, the maximum number of packets that can be in the system at any time is $\mathrm{K}$, and any additional packet are refused entry to system will depart immediately without service.

Example:

\section{Weighted Fair Queue}

WFQ calculates the finishing time all the packets and served based on the finishing time of the packets. WFQ is a dynamic process that divides bandwidth among queues based on weights. This process I designed so fair, such that WFQ ensures that all traffic is treated fairly with regard is weight. WFQ can prevent high-bandwidth traffic form over whelminutesg the resources of a network.

\begin{tabular}{|c|c|c|c|c|}
\hline Packet & Arrival Time & Length & Finishing Time & Output Order \\
\hline A & 0 & 8 & 8 & 1 \\
\hline B & 5 & 6 & 11 & 3 \\
\hline C & 5 & 10 & 10 & 2 \\
\hline D & 8 & 9 & 20 & 7 \\
\hline E & 8 & 8 & 14 & 4 \\
\hline F & 10 & 6 & 16 & 5 \\
\hline G & 11 & 10 & 19 & 6 \\
\hline H & 20 & 8 & 28 & 8 \\
\hline
\end{tabular}

\begin{tabular}{l|l|l}
$\mathrm{F}$ & $\mathrm{A}$
\end{tabular}

\begin{tabular}{|l|l|l|l|}
\hline $\mathrm{H}$ & $\mathrm{D}$ & $\mathrm{B}$ \\
\hline
\end{tabular}

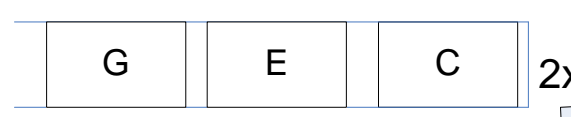

Input Queues

\section{Fair Queing}

\section{Weight is 2}

Figure 11: Finish(i)=Max $(\operatorname{Arrive}(i)$, Finish(i-) $)+$ Length/weight 
Table 3: Traffic Characteristics of IOT Applications[47]

\begin{tabular}{|c|c|c|}
\hline Layer & Techniques & Process \\
\hline \multirow{2}{*}{ Physical } & Grouping & To group the data comes from various devices \\
\hline & Router & Split the data into different IoT access point \\
\hline \multirow{3}{*}{ Network } & \multirow{3}{*}{ IoT Access Point } & Received packets from sensor through internet \\
\hline & & Classify the flow based on Nature of data \\
\hline & & Allocates the data flow into the buffer queues \\
\hline \multirow{6}{*}{ Data } & \multirow{2}{*}{ Buffer } & Store the data based on the flow types or traffic types \\
\hline & & Identify the traffic class of each packet \\
\hline & \multirow{4}{*}{ Weighted Fair Queue } & Fixed weight based on the Traffic \\
\hline & & Divides queue bandwidth based on weight of packet \\
\hline & & Execute the packet based on the finishing time \\
\hline & & Prevent high bandwidth traffic delay \\
\hline
\end{tabular}

\section{CONCLUSIONS}

The principle inspiration driving this research is to recognize the significance of IoT applications, for example smart home and buildings, smart health care, smart environment, smart city, smart energy and grid, smart transportation and mobility, smart manufacturing and retail, smart agriculture. Quality of Service (QoS) oversees information traffic to lessen bundle misfortune, idleness and jitter on the system. QoS controls and oversees organize assets by setting needs for explicit kinds of information on the system. It's important to decrease the system traffic and postpone fluctuation happens from heterogonous devices in different IoT applications, speed up and dependability of the information on the system. In this research QoS issues like jitter (delay variance) and traffic rate are recognized dependent on 8 applications with 40 services. A preventive model on QoS in IoT application proposed to handle various levels of real-time traffic and delay tolerant traffic with in sensor network. The proposed model is incorporated by three layers. The primary layer is the physical layer used to interface and gathering the information originates from different physical devices. The second layer is the system (or) data layer used to separate the information utilizing IoT access point and send the information to the buffer queue. The last layer is the information (or) data layer used to assign the different traffic streams into the buffer queues, Weighted Fair Queue Scheduling used to fix the weight dependent on the traffic; separates the line transfer speed dependent on loads of the every packet and execute the bundle dependent on the completing time. This model encourages the client to send the information in IoT applications with less time and low delay. This exploration encourages the researcher to distinguish the QoS issues in IoT application to tackle the issues with booking calculation. In future it is important to confirm the Quality of Service in IoT applications with WFQ algorithm, new algorithm going to implement based on the simulation tools and its results.

\section{REFERENCES}

1. M. A. Ezechina, K. K. Okwara, C. A. U. Ugboaja.The IoT (Iot): “A Scalable Approach to Connecting Everything”. The International Journal of Engineering and Science4(1) (2015)09-12.

2. http://www.meraevents.com/event/iot-workshop

3. http://www.nxp.com/assets/documents/data/en/white-papers/INTOTHNGSWP.pdf

4. Saranya C. M., Nitha K. P., “Analysis of Security methods in IoT”.International Journal on Recent and Innovation Trends in Computing and Communication,Volume 3, Issue4;April 2015.

5. Sapandeep Kaur, Ikvinderpal Singh. “A Survey Report on IoT Applications”. International Journal of Computer Science Trends and TechnologyVolume 4,Issue 2, Mar -Apr 2016. BOMBALE, UL, and SANJIVANI TUKARAM IKKE. "DESIGN AND 
IMPLEMENTATION OF POWER EFFICIENT SYSTEM USING IOT BASED WIRELESS SENSOR FOR ENVIRONMENT MONITORING."International Journal of Electronics, Communication \& Instrumentation Engineering Research and Development (IJECIERD) 9. 1, Jun 2019, 17-24

6. https://www.thingworx.com/ecosystem/markets/smart-connected-systems/smart-cities/

7. EimanAl Nuaimil et al., "Applications of big data to smart cities.” Journal of Internet Services and Applications2015.

8. http://www.7wdata.be/article-general/how-big-data-and-internet-of-things-builds-smart-cities/

9. A. Murray, M. Minutesevich, and A. Abdoullaev. "Being smart about smart cities”.KM World, October 2011.

10. Farheen Fatima, at el.,IoT: A Survey on Architecture, Applications, Security, Enabling Technologies, Advantages \& Disadvantages. International Journal of Advanced Research in Computer and Communication EngineeringVol. 4, Issue 12, December 2015.

11. http://www.connected-living.org/content/4-information/4-downloads/4-studien/20-minutesd-commerce-smart-homescompanies-and-solutions-2014/minutesd-commerce_smart-homes-companies-and-solutions-2014_glo_122014.pdf

12. http://www.gsma.com/connectedliving/wpcontent/uploads/2012/03/vision20of20smart20home20report.pdf

13. Jukka Suhonen. "Experiences and Future Plans for WSN-enabled Service Development in Home Environment". Realin white paper 2013.

14. Amrita Sajja, D.K. Kharde, Chandana Pandey. “A Survey on efficient way to Live: Smart Home-It's an IoT”.ISAR -International Journal of Electronics and Communication Ethics,Volume 1. Issue 1,2016.Murty, A., M. Satyanarayana, and I. Devi. "Compressor Health Monitoring using IOT." International Journal of Mechanical and Production Engineering Research and Development 8.3 (2019): 117-124.

15. Gabriele Lobaccaro, Salvatore Carlucci and Erica Löfström (2016). “A Review of Systems and Technologies for Smart Homes and Smart Grids".www.mdpi.com/journal/energies.

16. Tiago D. P. Mendes et al., "Smart Home Communication Technologies and Applications: Wireless Protocol Assessment for Home Area Network Resources". Energies 2015.

17. http://energy.gov/sites/prod/files/oeprod/DocumentsandMedia/DOE SG Book Single Pages(1).pdf

Satyanarayana, K. N. V., et al. "Mobile app \&iot based smart weather station." International Journal of Electronics, Communication and Instrumentation Engineering Research and Development (IJECIERD) 7.4 (2017): 1-8.

18. "Smart Grid enabling energy loficiency -carbon transition", https://www.gov.uk/government/uploads/system/uploads/attachment_data/file/321852/Policy_Factsheet_-

Smart_Grid_Final_BCG_pdf MATHUR, GEETIKA, HARSHIT SHARMA, and RISHABH PANDEY."A STUDY ON SELFDRIVING CAR AN APPLICATION OF IoT."International Journal of Computer Networking, Wireless and Mobile Communications (IJCNWMC). 9. 1, Jun 2019, 25-34

19. Ramyar Rashed Mohasselet al., “A survey on Advanced Metering Infrastructure”. International Journal of Electrical Power \&Energy Systems63(2014) 473-484.

20. Rosario Miceli. Energy Managementand Smart Grids.Energies 2013.

21. David "How Niewolny. IoT Is Revolutionizing Healthcare". https://cache.freescale.com/files/corporate/doc/white_paper/IOTREVHEALCARWP.pdf

22. Bill Chamberlin. "Healthcare IoT: 18 trends to watch in2016. IBM Center for Applied 
Insights".https://ibmcai.com/2016/03/01/healthcare-internet-of-things-18-trends-to-watch-in-2016

23. Mobyen Uddin Ahmed, Mats Björkman, Aida Čaušsević, Hossein Fotouhi, and Maria Lindén. "An Overview on the IoT for Health Monitoring Systems".https://www.researchgate.net/publication/281062554

24. Vahid Mirzabeiki. "An Overview of the Freight Intelligent Transportation Systems; Division of Logistics and Transportation, Chalmers University of Technology". http://www.bth.se/tek/intelligent_gods.nsf/bilagor/Mirzabeiki,2010,ITS\%20World\%20Busan_pdf/\$file/Mirzabeiki,2010,ITS\%2 oWorld\%20Busan.pdf

25. Manoop Talasila, RezaCurtmola, and Cristian Borcea. Mobile Crowd Sensing; New Jersey Institute of Technology. https://web.njit.edu/ mt57/publications/Chapter4.pdf

26. Georgios Chatzimilioudis, et al., "Crowdsourcing with Smartphones". IEEE Internet Computing 2017.

27. Marc Benioff. "Industrial IoT: Unleashing the Potential of Connected Products and Services",January2015.http://www3.weforum.org/docs/WEFUSA_IndustrialInternet_Report2015.pdf

28. https://www.munichre.com/site/corporate/get/documents_E352744188/mr/assetpool.shared/Documents/0_Corporate\%20Web site/1_The\%20Group/Focus/Emerging\%20Risks/CROF-ERI-2015-The-Smart-Factory.pdf

29. https://atos.net/content/dam/global/documents/your-business/atos-smart-factory-ascent-thought-leadership-paper-july2014.pdf

30. Arko Djajadi, Member. Ambient "Environment quality monitoring Using IoTSensor Network.Interworking” Indonesia JournalVol. 8, No.1 (2016).

31. D. Bhattacharjee and R. Bera. "Development of smart detachable wireless sensing system for environmental monitoring”. International journal on smart sensing and intelligent systems Vol.. 7, No. 3, September 2014.

32. Peng Jiang, Hongbo Xia, Zhiye He and Zheminutesg Wang. "Design of a Water Environment Monitoring System Based on Wireless Sensor Networks".Sensors 9 (2009) 6411-6434; doi:10.3390/s90806411

33. Nomusa Dlodlo. “Adopting the IoT technologies in environmental management in South Africa”.International Conference on Environment Science and Engieering, IPCBEE Vol.3 2,(2012)IACSIT Press, Singapore.

34. Delphine Christin, Andreas Reinhardt, Parag S. Mogre, Ralf Steinmetz. "Wireless Sensor Networks and the IoT: Selected Challenges".http://www.ti5.tu-harburg.de/events/fgsn09/proceedings/fgsn_031.pdf

35. http://www.gov.uk/government/uploads/system/uploads/attachment_data/file/409774/14-1230-internet-of-things-review.pdf

36. http://senseable.mit.edu/papers/pdf/20150228_Kumar_etal_RiseLowcost_EnvironmentInternational.pdf

37. http://auskogroup.com/how-iot-is-changing-the-waste-industry

38. P.Susmitha, G.Sowmyabala. "Design and Implementation of Weather Monitoring and Controlling System".International Journal of Computer ApplicationsVolume 97, No.3, July 2014.

39. http://iotworm.com/internet-of-things-technology-weather-forecasting/

40. Curioni, F. Murtas, M. Silari.Internet of Sensors. Politecnicodi Milano, Milano,Italy.https://indico.cern.ch/event/470460/attachments/1303283/1948255/P10_TWD2016_Curioni.pdf

41. M. Dragusin, D. Stanga, D. Gurau, E. Ionescu. Radiation monitoring under emergency conditions.Rom. Journal. Phys.Vol. 59, Nos. 9-10 (2014) 891-903. 
42. "IAEA Safety Standards for protecting people and environment; Environmental and Source Monitoring for Purposes of Radiation Protection"; Safety Guide No. RS-G-1.8,IAES internaltional atomic negry agency. http://www ns.iaea.org/standards/feedback.htm

43. http://www.undp.org/content/dam/mozambique/docs/Community\%20based\%20BP.pdf

44. https://econsultancy.com/internet-of-things-healthcare/

45. Ullah, Zakir et al. "A Preview on IoT (IOT) and its Applications." 2019 2nd International Conference on Computing, Mathematics and Engineering Technologies (iCoMET) (2019): 1-6.

46. Mocnej, Jozef, et al. "Network Traffic Characteristics of the IoT Application Use Cases, 2018.

47. Azlan, Syed Nor, and Syarifah Ezdiani. “Adaptive Quality of Service for IoT-based Wireless Sensor Networks”. Diss. Auckland University of Technology, 2018.

48. White, Gary, Vivek Nallur, and Siobhán Clarke. "Quality of service approaches in IoT: A systematic mapping." Journal of Systems and Software 132 (2017): 186-203. 